\title{
Determination of benzene and toluene in blood by means of a syringe-equilibration method using a small amount of blood
}

\author{
AKIO SATO, TAMIE NAKAJIMA, and YUKIKO FUJIWARA \\ Department of Hygiene, Shinshu University Faculty of Medicine, Matsumoto, Japan
}

\begin{abstract}
Sato, A., Nakajima, T., and Fujiwara, Y. (1975). British Journal of Industrial Medicine, 32, 210-214. Determination of benzene and toluene in blood by means of a syringe-equilibration method using a small amount of blood. A gas chromatographic determination of benzene and toluene in blood with a small amount of blood sample, 0.02 or $0.1 \mathrm{ml}$, is described.

In the method an aliquot of the blood sample in a sealed hypodermic syringe of $2 \mathrm{ml} \mathrm{ca-}$ pacity is equilibrated at $37^{\circ} \mathrm{C}$ in a thermo-regulated water-bath. After establishing equilibrium $1 \mathrm{ml}$ of overlying air is submitted to gas chromatographic analysis.

The value of this method was verified by experiments in which men, rabbits, and rats were exposed to benzene and toluene mixtures of various concentrations.
\end{abstract}

Since the intensity of effect of a toxic substance is associated with its concentration at the site of action, there is likely to be a corresponding relationship between the toxic effect and the blood level of the substance (Levy and Gibaldi, 1972). There have been very few investigations concerning toxicity of organic solvent vapours, correlating quantitatively the time course of blood levels in the body with the time course of toxic effects. This is largely because of the lack of an efficient method of quantitative analysis by which the amount of vapour in small quantities of blood can easily and accurately be determined in a short time. Therefore there is a great need to develop such a method.

A simple way to analyse the blood concentration of volatile substances is by injecting a minute quantity of the blood directly into a gas chromatograph (Lowe, 1964; Yokota et al., 1967; Sato, 1967; Okuda, 1968; Szadkowski et al., 1970/1971; Cousins and Mazze, 1972). Although this method offers the advantage of rapidity of analysis and apparent simplicity, it is not without difficulties which include injection hazards, baseline disturbances, and distortion of the peak shape (Jones, Molloy, and Rosen,
1972). Injecting directly whole blood containing water, lipids, and protein leads to contamination of the injection port, column, and detector. In gas chromatography therefore a gaseous sample should preferably be used (Yamamura et al., 1966; Butler, Kelly, and Zapp, 1967; Fink and Morikawa, 1970).

Sato (1971) showed that it was possible, by means of a gas chromatographic equilibration method using $1 \mathrm{ml}$ of blood, to separate and detect quantitatively $0.02 \mu \mathrm{g} / \mathrm{ml}$ of benzene, $0.04 \mu \mathrm{g} / \mathrm{ml}$ of toluene, and $0.1 \mu \mathrm{g} / \mathrm{ml}$ of m-xylene, each concentration corresponding to a peak height of $1 \mathrm{~cm}$ on the chromatogram. In an experiment where five healthy human males were exposed to benzene $25 \mathrm{ppm}$, toluene $100 \mathrm{ppm}$, and m-xylene $150 \mathrm{ppm}$ for two hours, Sato demonstrated that this method gave accuracy and sensitivity of value in experimental studies. However, in experiments using small animals, such as rats or mice, it is difficult to collect $1 \mathrm{ml}$ of blood repeatedly without causing severe damage to the animal. It is desirable, therefore, to conduct the analysis with a smaller amount of blood.

The principle of the present gas chromatographic equilibration method is as follows: 
Blood, vol A, containing a solvent in concentration $\mathrm{x}$, is equilibrated with air in a closed vessel of capacity V. The solvent is distributed between the blood and air with a partition coefficient, blood/air, of $\lambda$. Let $y$ be the concentration in air, volume $V-$ $A$; and $z$ be the concentration remaining in the blood. The total quantity of solvent in the system is conserved, hence, by equating quantities before and after the equilibration, we obtain

$$
\mathbf{A x}=\mathbf{A z}+(\mathbf{V}-\mathbf{A}) \mathbf{y}
$$

By definition:

From (1) and (2):

$$
\lambda=\mathbf{z} / \mathbf{y}
$$

$$
x=(\lambda+V / A-1) y
$$

Thus the concentration in the blood can be estimated from the concentration in the air, and the relationship depends mostly on the ratio of the volume of the vessel to that of blood, and not on the absolute volumes. A very small volume of blood in a small vessel can therefore be used.

This brief report deals with a method for estimating concentrations of benzene and toluene in blood with a small amount of blood sample $(0.1$ or 0.02 $\mathrm{ml}$ ) by means of the gas chromatographic equilibration technique using a $2 \mathrm{ml}$ hypodermic syringe as the equilibration vessel.

\section{Method}

\section{Preparation of standard samples}

Stored human blood obtained from the blood bank was used for preparing standard samples. A known volume of a liquid solvent was added to the blood in a volumetric flask, using a microsyringe (Hamilton, Model 705). The blood in the closed flask was then stirred with a magnetic stirrer for about 30 min to obtain a homogeneous standard sample containing the solvent in a known concentration. In the case of benzene, for instance, $10 \mu \mathrm{l}$ were added to $100 \mathrm{ml}$ of blood to dissolve. One, two and four millilitres of this blood were then each made up to $100 \mathrm{ml}$ by adding more blood, to prepare a series of standards containing $0.088,0.176$, and 0.352 $\mathrm{mg} / \mathrm{dl}$ of benzene respectively. A calibration curve was made with this series of standard samples.

\section{Equilibration vessel}

Vial According to the method of Sato (1971), a hole of $1 \mathrm{~cm}$ diameter was made in the plastic screw cap of a glass vial of $16.5 \mathrm{ml}$ capacity. The inner cover of the cap was made of rubber sheeting with a thickness of $2 \mathrm{~mm}$ so as to fit the cap, and aluminium-foil of the same size was attached to its lower surface as a seal. One millilitre of blood sample was injected into the vial, which was then closed with the screw cap as quickly as possible.

Syringe For a $0 \cdot 1 \mathrm{ml}$ blood sample (Fig. 1) an interchangeable $2 \mathrm{ml}$ hypodermic syringe with a rubber cap attached to the end was used. In order to prevent the adsorption of solvent vapours on the rubber cap, the space between the barrel of the syringe and the rubber cap was filled with mercury. Through the rubber cap and mercury was inserted an injection needle to act as an air-

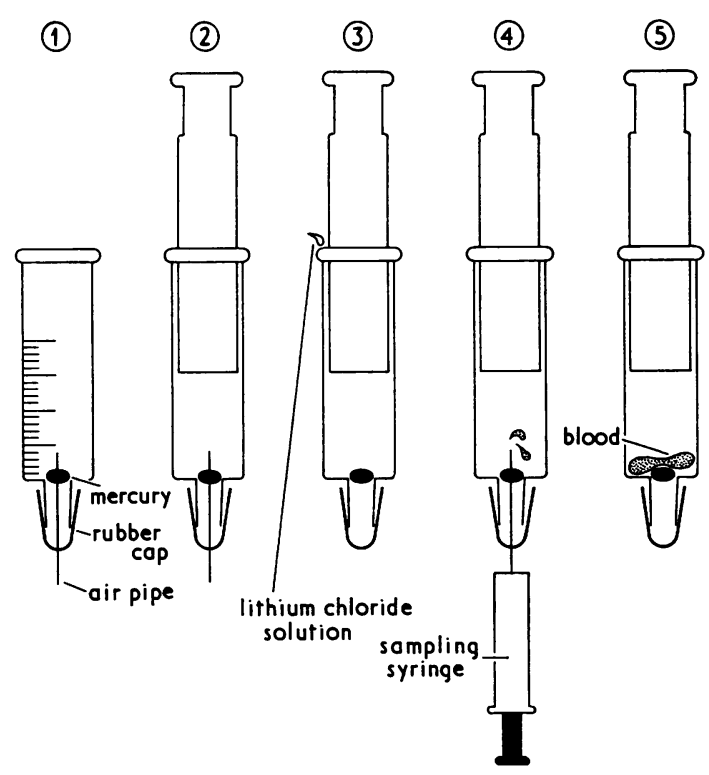

FIG. 1. Procedure for $0.1 \mathrm{ml}$ blood samples using syringe as equilibration vessel.

pipe into the syringe. The plunger was adjusted to give a volume of $1.5 \mathrm{ml}$ air in the syringe, and then the air-pipe was removed with the plunger fixed in that position. The gap between the barrel and plunger was sealed with a drop of saturated lithium chloride solution, which served not only as an air seal but also as a lubricant. Into this equilibration syringe was injected through the rubber cap a $0.1 \mathrm{ml}$ blood sample which had been taken into a small sampling syringe of $0.25 \mathrm{ml}$ capacity.

For a $0.02 \mathrm{ml}$ blood sample an interchangeable syringe of $2 \mathrm{ml}$ capacity with a rubber cap and an air-pipe was used as the equilibration vessel. In this case, the blood sample was taken into a Sahli pipette, and was transferred into the barrel of the syringe by blowing. The volume of air in the syringe was then adjusted to $1.5 \mathrm{ml}$ by inserting the plunger. The air-pipe was removed, and the gap between the barrel and the plunger was sealed with saturated lithium chloride solution.

\section{Measurement}

The equilibration vessels, vial or syringe containing the blood sample were allowed to stand in a thermoregulated water-bath at $37^{\circ} \mathrm{C}$ for about $30 \mathrm{~min}$ to establish equilibrium between the gas and liquid phases. When equilibrium was reached, $1 \mathrm{ml}$ of the air in the vessel was withdrawn through its rubber septum into an air-tight syringe and injected into the injection port of a gas chromatograph equipped with a hydrogen flame ionization detector. The operating conditions of the gas chromatograph were as follows:

Column A $2 \mathrm{~m}$ stainless steel tube packed with $10 \%$ polyethylene glycol 400 on Celite 545 ; carrier gas, $\mathrm{N}_{2}$ at 70 $\mathrm{ml} / \mathrm{min}$; column temperature, $80^{\circ} \mathrm{C}$; injection temperature, $150^{\circ} \mathrm{C}$.

The blood concentration of the solvent vapour in an 
unknown sample was calculated by comparing the peak height on the chromatogram with the calibration curve obtained with the standard sample.

\section{Results and discussion}

In Table 1 are compared the results with a $1.0 \mathrm{ml}$ blood sample and $16.5 \mathrm{ml}$ vial (volume of air: $15.5 \mathrm{ml}$ ), and with a $0.1 \mathrm{ml}$ blood sample and $2 \mathrm{ml}$ syringe (volume of air: $1.5 \mathrm{ml}$ ). No significant difference was found between the two cases, which indicates that by using an equilibration vessel onetenth as large, the same efficiency of measurement can be obtained with one-tenth as much blood. This means that equation (3) is confirmed.

The concentration-peak height curves made with the series of standard blood samples are shown in Fig. 2. No serious deviation from linearity was

TABLE 1

COMPARISON OF RESUlts ObTAINED From Vial and Syringe Methods Using a Standard SAMPLE OF $0 \cdot 1 \mu \mathrm{l} / \mathrm{dl}($ ATtenUATION $\times 5)$

\begin{tabular}{|c|c|c|c|}
\hline \multirow{2}{*}{\multicolumn{2}{|c|}{ Method }} & \multicolumn{2}{|c|}{ Mean peak height $\pm S D(n=20)$} \\
\hline & & Benzene & Toluene \\
\hline $\begin{array}{l}\text { Vial } \\
\text { Syringe }\end{array}$ & $\begin{array}{l}\ldots \\
\ldots\end{array}$ & $\begin{array}{l}8.85 \pm 0.358 \\
9.03 \pm 0.315\end{array}$ & $\begin{array}{l}4.47 \pm 0.196 \\
4.56 \pm 0.166\end{array}$ \\
\hline
\end{tabular}

observed in the concentration-peak height relationship. In the syringe-equilibration method, the deviation from the regression line was noticeably greater in the $0.02 \mathrm{ml}$ blood samples than in the $0 \cdot 1 \mathrm{ml}$ samples. It was sometimes difficult to transfer completely the sample from the Sahli pipette into the syringe by blowing, which might have influenced the result. In any case, however, the coefficient of variation of the analysis is not more than $5 \%$.

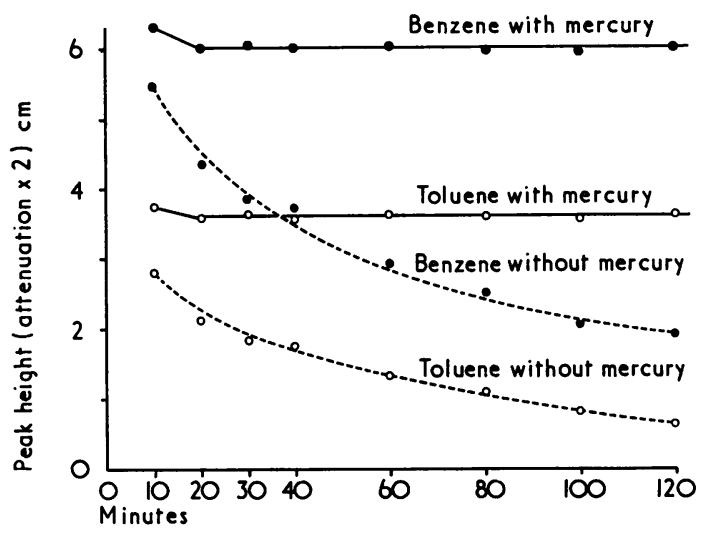

FIG. 3. Changes in gaseous concentration in relation to equilibration time $(0.02 \mathrm{ml}$-syringe method using a standard sample of $0 \cdot 1 \mu \mathrm{l} / \mathrm{dl})$.

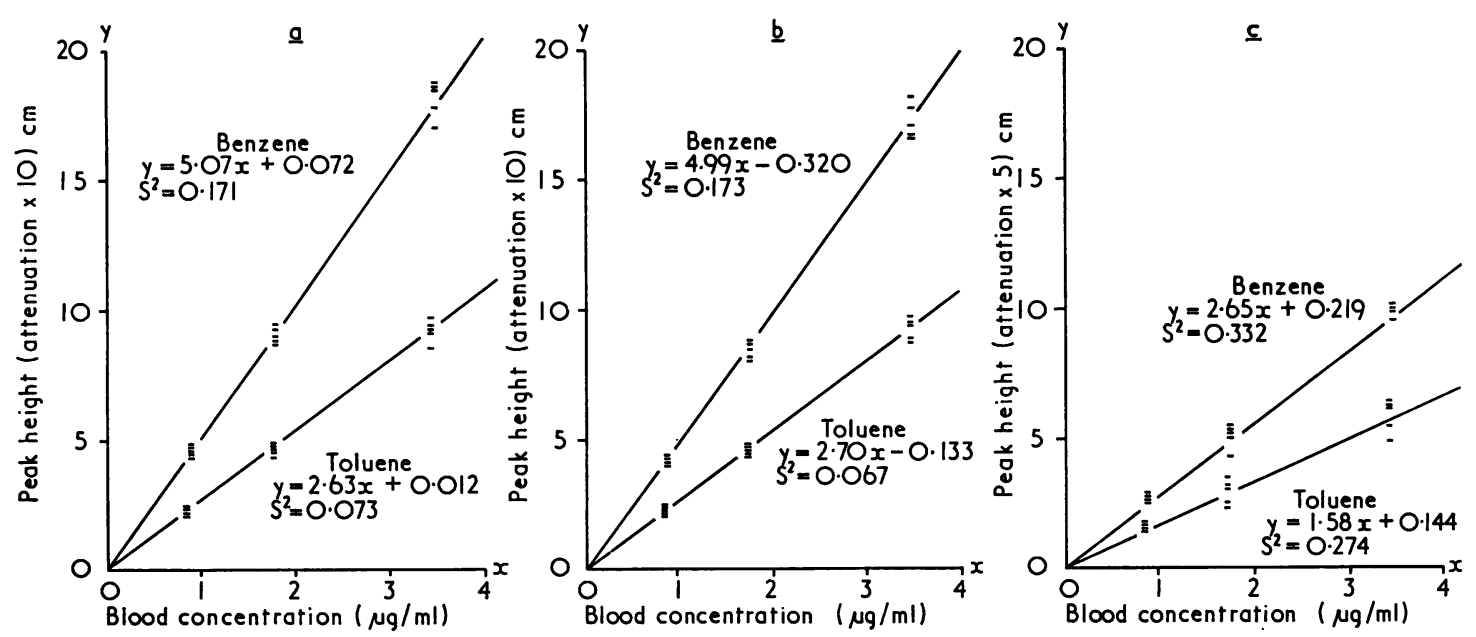

FIG. 2. Relationship between blood concentration (x) and peak height (y).

a: 1 ml-vial method.

b: $\mathbf{0} \cdot 1 \mathrm{ml}$-syringe method.

c: $0.02 \mathrm{ml}$-syringe method.

$\mathrm{s}^{2}$ is mean square of deviation from linear regression. 
TABLE 2

Loss of Solvents After Sampling a Standard Sample of $0.1 \mu \mathrm{l} / \mathrm{dl}$ in Vials

\begin{tabular}{|c|c|c|c|c|c|c|}
\hline \multicolumn{2}{|c|}{ Hours } & 0 & 6 & 12 & 24 & 48 \\
\hline $\begin{array}{l}\text { Benzene } \\
\text { Toluene }\end{array}$ & $\begin{array}{l}\ldots \\
\ldots\end{array}$ & $\begin{array}{l}9.05 \pm 0.289 \\
4.54 \pm 0.220\end{array}$ & $\begin{array}{l}8.90 \pm 0.303 \\
4.51 \pm 0.182\end{array}$ & $\begin{array}{l}8.89 \pm 0.394 \\
4.46 \pm 0.195\end{array}$ & $\begin{array}{l}9 \cdot 12 \pm 0.248 \\
4.58 \pm 0.135\end{array}$ & $\begin{array}{l}8.88 \pm 0.413 \\
4.52 \pm 0.062\end{array}$ \\
\hline
\end{tabular}

Figures in the table are mean peak height $\pm S D(n=5)$ at attenuation $\times 5$.

Furthermore, the following points were found when examining the present method:

1. As shown in Fig. 3, the concentrations of benzene and toluene in the gas phase became stable about 20 min after being equilibrated, and there was no change in concentration for two hours thereafter.

2. It was not an easy task to fill the space between the syringe and the rubber cap with mercury. Without mercury however the gas phase concentration of benzene and toluene, which is easily adsorbed to rubber, was found to decrease with lapse of equilibration time (Fig. 3). For the same reason, aluminium-foil was indispensable for the analysis using a vial as the equilibration vessel.

3. The purpose of sealing the gap between the barrel and the plunger with a drop of saturated lithium chloride solution was to keep the syringe air-tight by its viscosity and also to prevent blood from adhering to the inner surface of the syringe. In some cases blood taken in a dry syringe caused the plunger to seize in the barrel, making gas sampling difficult. One drop of this air seal was distributed around the surface of the barrel and plunger and came in contact with the air and blood in the syringe. Although benzene and toluene are almost insoluble in satu- rated lithium chloride solution, the effect of the solution itself on the blood/air partition coefficient for these vapours had to be clarified. $0.01 \mathrm{ml}$ of saturated lithium chloride solution was placed in a vial and $1.0 \mathrm{ml}$ of standard material $(0 \cdot 1 \mu \mathrm{l} / \mathrm{dl})$ was added to make a sample. Gas phase concentrations of benzene and toluene were each determined in 20 samples. The mean peak heights \pm standard deviation for benzene and toluene were $8.95 \pm 0.339$ and $4 \cdot 50 \pm 0 \cdot 170$, respectively. There was no significant difference between the above results and the results shown in Table 1. It can be said therefore that the effect of a small amount of saturated lithium chloride solution on the blood/air partition coefficient for these solvent vapours is negligible.

4. Capped vials containing $1 \mathrm{ml}$ of a standard material $(0.1 \mu \mathrm{l} / \mathrm{dl})$ were stored in a refrigerator at $4^{\circ} \mathrm{C}$. The vapour concentrations in the gas phase in the vials were then determined at $0,6,12,24$, and 48 hours of storage. No serious change in vapour concentration was found with duration of storage (Table 2).

5. The present method can be carried out with several common analytical tools such as glass vials and syringes, and no particular skill is required. More-

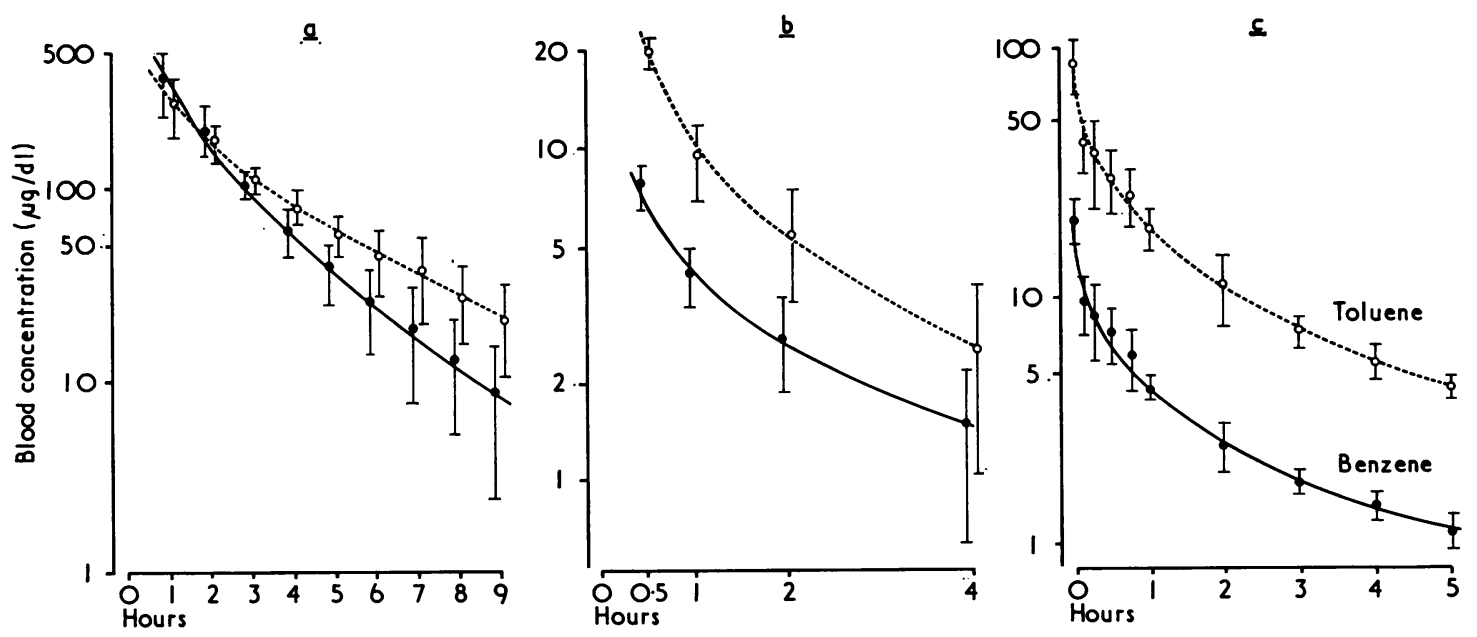

FIG. 4. Application of methods to experimental exposure of $a$ rats, $b$ rabbits, and $c$ men.

Vertical lines represent mean value \pm SD. 
over, many samples can be analysed in a few hours. The value of the method was studied using men, rabbits, and rats all of whom were exposed to a mixture of benzene and toluene of various concentrations. After exposure, blood levels in each case were determined by the $1 \mathrm{ml}$-vial, $0.1 \mathrm{ml}-$ syringe, and $0.02 \mathrm{ml}$-syringe methods. The time courses of blood level thus obtained are shown in Fig. 4 (a) to (c) in terms of the mean and standard deviation: (a) Five female rats (Wistar) were each exposed to a solvent mixture containing benzene and toluene $500 \mathrm{ppm}$ for two hours. The blood levels of these organic solvents were determined by taking $0.02 \mathrm{ml}$ of blood with a Sahli pipette from the tail vein every hour after the exposure. (b) Three female rabbits were exposed to a mixture of benzene $50 \mathrm{ppm}$ and toluene $200 \mathrm{ppm}$ for two hours. The blood levels of these solvents were determined in $0.1 \mathrm{ml}$ of blood collected from the ear vein 30,60 , 120 , and $240 \mathrm{~min}$ after the exposure. (c) Three healthy young men were exposed to air containing a mixture of benzene $25 \mathrm{ppm}$ and toluene $100 \mathrm{ppm}$ for two hours. After the exposure, blood levels were determined by the vial-equilibration method using $1 \mathrm{ml}$ of blood collected from the cubital vein at previously selected intervals.

\section{References}

Butler, R. A., Kelly, A. B., and Zapp, J. (1967). The determination of hydrocarbon anesthetics in blood by gas chromatography. Anesthesiology, 28, 760-763.

Cousins, M. J. and Mazze, R. I. (1972). A rapid directinjection method for measuring volatile anesthetics in whole blood. Anesthesiology, 36, 293-296.

Fink, B. R. and Morikawa, K. (1970). A simplified method for the measurement of volatile anesthetics in blood by gas chromatography. Anesthesiology, 32, 451-455.

Jones, P. L., Molloy, M. J., and Rosen, M. (1972). A technique for the analysis of methoxyflurane in blood by gas chromatography. British Journal of Anaesthesia, 44, 124-130.

Levy, G. and Gibaldi, M. (1972). Pharmacokinetics of drug action. Annual Review of Pharmacology, 12, 85-98.

Lowe, H. J. (1964). Flame ionization detection of volatile organic anesthetics in blood, gases and tissues. Anesthesiology, 25, 808-814.

Okuda, Y. (1968). A gas chromatographic analysis of the concentration of volatile anaesthetics in blood by an ampoule-crash method (in Japanese). Japanese Journal of Anaesthesiology, 17, 391-397.

Sato, A. (1967). Gas chromatographic determination of trichloroethylene and toluene in blood by direct injection method. Medical Journal of Shinshu University, 12, 299-311.

-, (1971). Gas chromatographic determination of benzene, toluene and m-xylene in blood by an equilibration method (in Japanese). Japanese Journal of Industrial Health, 13, 173-179.

Szadkowski, D., Schröter, U., Essing, H. G., Schaller, K. H., and Lehnert, G. (1970/71). Ein gaschromatographisches Nachweisverfahren für Benzol und Toluol in kleinsten Blutproben. Internationales Archiv für Arbeitsmedizin, 27, 300-308.

Yamamura, H., Wakasugi, B., Sato, S., and Takebe, Y. (1966). Gas chromatographic analysis of inhalation anesthetics in whole blood by an equilibration method. Anesthesiology, 27, 311-317.

Yokota, T., Hitomi, Y., Ohta, K., and Kosaka, F. (1967). Direct injection method for gas chromatographic measurement of inhalation anesthetics in whole blood and tissues. Anesthesiology, 28, 1064-1073.

Received for publication 23 July 1974

Accepted for publication 30 October 1974 